\title{
Knowledge, Attitude and Treatment Seeking Behavior for Malaria in May-Aynee Administration, Eritrea
}

\author{
Amanuel Kidane Andegiorgish ${ }^{1 *}$, Eyob Azeria Kidane ${ }^{1}$, Beilul Eyob Welday ${ }^{2}$, Medhanie Weldeghiergis \\ Weldekidan $^{3}$, Nahom Yosef Tekle ${ }^{3}$ and Lidiya Fisshasion Sibahtu ${ }^{3}$ \\ ${ }^{1}$ Asmara College of Health Sciences, Eritrea \\ ${ }^{2}$ National malaria control program, Eritrea
}

${ }^{3}$ Zonal malaria control officers, Eritrea

*Corresponding author: Amanuel Kidane Andegiorgish, School of public health, Asmara College of Health Sciences, Eritrea

\begin{tabular}{l}
\hline ARTICLE INFO \\
\hline Received: 梆 October 10, 2019 \\
Published: 亚October 17, 2019 \\
\hline
\end{tabular}

Citation: Amanuel Kidane A, Eyob Azeria K, Beilul Eyob W, Medhanie Weldeghiergis W, Nahom Yosef T, Lidiya Fisshasion S. Knowledge, Attitude and Treatment Seeking Behavior for Malaria in MayAynee Administration, Eritrea. Biomed J Sci \& Tech Res 22(1)-2019. BJSTR. MS.ID.003700.

Keywords: Knowledge; Attitude; Malaria; Households; Treatment Seeking Behavior

\section{ABSTRACT}

Objective: Malaria is an entirely preventable and treatable disease. However, due to lack of adherence to the preventive measures and delay in early treatment, it has become one of the leading public health problems. The general objective was to assess knowledge, attitude and early treatment seeking behavior about malaria among the communities residing in May-Aynee administration, Eritrea.

Method: We conducted a community based cross sectional study. Using systematic random sampling proportional to the size of households in the community, 243 households were selected. Data was collected using a pre-tested questionnaire and analyzed with SPSS (Version-20). P-value less than 5\% was considered statistically significant.

Results: All respondents knew malaria's fatal outcome if untreated. More than half (55.6\%) were aware of preventive and treatment measures, mainly through health workers. Most of them recognized mosquito bite as cause (91.8\%) and fever as symptom (84\%). Of all respondents, $75.4 \%$, mostly with higher educational level and living close to health facilities, had adequate knowledge about malaria. Almost all (98.8\%) respondents stated they would seek treatment from health facility when symptoms appear. However, only 39.9\% would do so within 24 hours. Around half of respondents $(47.7 \%)$ experienced malaria symptoms in the past six months. Most of them (90.6\%) sought treatment from health facility. However, only $22.4 \%$ did so within 24 hours. Long distance between home and health facility was significantly associated with such delay.

Conclusion: Most respondents had adequate knowledge regarding cause, symptom, outcome and treatment in relation to malaria. However, small proportion of them sought treatment promptly. Health promotion activities should be implemented to enhance early treatment of the disease.

\section{Introduction}

\section{Background}

Malaria is known to be a major cause of morbidity and mortality globally, with an estimated 3.2 billion people living in malarious areas, mostly in low-income countries [1]. According to the 2015 World Malaria Report, around 214 million cases and 438,000 deaths of malaria were reported [2]. Similarly, in 2016, there were nearly 215 million patients and 435, 000 deaths worldwide [3]. An estimated $88 \%$ of cases and $90 \%$ deaths of malaria were reported from Africa [4]. Early diagnosis and prompt treatment can cure the disease and reduce mortality attributed from malaria [5]. World Health Organization has emphasized to reduce the burden, complication and transmission of malaria through diagnosis and treatment within 24 hours and states that a delay would increase 
the already high impact of the disease [6-8]. Malaria is a great public health concern in all endemic areas of Eritrea. Around $70 \%$ of the Eritrean population live in areas where malaria is transmitted [9].

The government of the state of Eritrea has been constructing several health facilities to attain sustainable development goal (SDG-3) objectives by reducing the burden and eventually eliminating malaria [10]. Besides many health professionals have been trained to offer an equitable, easy and smooth delivery of healthcare to all communities in the country. In addition, the ministry of health has introduced community health agents (CHA) in villages and towns to provide primary care services. The cumulative effect of these approaches has reduced the incidence, health facility admission and deaths attributable to malaria $[6,8,11$ 14]. Despite the reduction in malaria morbidity and mortality, the disease remains a public health concern in most parts of the country threatening economic development. Success of malaria control efforts depends on knowledge, attitude and treatment seeking behaviors of people living in malarious areas [15]. Several countries have achieved significant progress in malaria control and elimination by empowering communities with knowledge so as to recognize the symptoms and to seek early treatment through health facilities [16-18]. The aim of this study was to investigate the level of knowledge, attitude and practice of community on early treatment seeking behavior on malaria.

\section{Methods}

\section{Study Design}

Community based cross-sectional study was conducted in May-Aynee administration. A structured questionnaire was used to collect information from representatives of households.

\section{Study Area}

May-Aynee is a subzone located about $78 \mathrm{~km}$ southeast of Asmara. It is one of the 12 subzones in Southern region of Eritrea. May-Aynee administration is one of the 11 administrations in MayAynee subzone. It consists of four villages and the town of MayAynee. Malaria is endemic in the administration. Rainfall is seasonal and extends between the months of June and September with the greatest intensity during July-August.

\section{Study Population}

May-Aynee administration has 575 households. There are three ethnic groups: Tigre, Tigrigna, and Saho. The livelihood of the population primarily relies on agriculture, pastoralism, and trade.

\section{Sample Size Determination}

A sample size of participants was determined using the formula $\mathrm{n}=\mathrm{z}^{2} \mathrm{qq} / \mathrm{d}^{2}$, where $\mathrm{n}$ is sample size, $\mathrm{p}$ (where is $\mathrm{p}$ in the formula) is the proportion of a population with the attribute of interest (0.5), q is 1-p, $\mathrm{d}$ is the degree of precision (0.05), $\mathrm{z}$ is the standard normal deviation (1.96), giving 384.16. Since the population size is small in comparison to the sample size, the population correction factor was introduced $\left(n_{2}=n / 1+n / N\right)$. Adding $5 \%$ contingency for non-response; 243 households were included. Using a systematic random sampling technique, households (Interval $=575 / 243$ $\approx 2.36$ ) were selected and one member of the household family (the husband, wife or adult>15years old) was interviewed (Table 1).

Table 1: Number of households proportionate to the size of villages.

\begin{tabular}{|c|c|c|}
\hline Village & No. of Households & Sample from Each Village \\
\hline May-Aynee town & 261 & 111 \\
\hline Emba-Arba & 83 & 35 \\
\hline Habenat & 155 & 64 \\
\hline Adi-Hufut & 29 & 13 \\
\hline Adi-Bari & 47 & 20 \\
\hline Total & 575 & 243 \\
\hline
\end{tabular}

\section{Data Collection}

A standardized questionnaire was adapted to the context of this study. Initially the questionnaire was developed in English and was translated to local language. The questionnaire included four sections - socio-demographic characteristics, knowledge, attitude, and early treatment seeking behaviors. Pilot study was carried out in Dieda $6 \mathrm{~km}$ east of May-Aynee two days prior to the actual study, and an amendment was done accordingly. Trained public health officers collected the data using face to face interview with the head of the household.

\section{Overall Knowledge Scores}

Knowledge on malaria was assessed based on three components: causes, signs and symptoms, and prevention of malaria. Each respondent got one score for correctly answering a question and zero otherwise. For questions with multiple responses, a score was given based on the number of correct responses. An overall knowledge score was calculated by adding up the scores of each respondent across all questions. Seventeen points were considered for malaria knowledge score. Using median as cutoff point, score greater than the median was considered as satisfactory and less than the median as unsatisfactory. Furthermore, a percent knowledge index (PKI) was calculated for each participant by summing the number of correct answers from the 17 items.

\section{Data Processing and Analysis}

Data were entered and analyzed using SPSS version 20. Categorical variables were described using frequencies and percentages while continuous variables were described using appropriate measures of central tendency and dispersion and were presented in the form of tables and graph. Chi-square and binary logistic regression were used to test for associations. Crude and adjusted odds ratio along with their $95 \%$ confidence intervals were presented, and $\mathrm{p}<0.05$ was considered statistically significant.

\section{Result}

\section{Socio-Demographic Characteristics of Respondents}

A total of 243 households participated in this study. Mean family size of the studied households was 5.2 persons. Nine-tenth 
(90.1\%) of the households were headed by females. The mean age of the study participants was 42.6 with a standard deviation (SD) of \pm 14.8 years. Forty-three percent of the study participants had primary education; while $41.2 \%$ had no formal education (Table 2 ).

Table 2: Baseline characteristics of respondents.

\begin{tabular}{|c|c|c|}
\hline Variable & Frequency $(\mathrm{N}=243)$ & Percent (\%) \\
\hline \multicolumn{3}{|c|}{ Gender } \\
\hline Male & 22 & 9.1 \\
\hline Female & 221 & 90.9 \\
\hline Age & 29 & 13 \\
\hline $20-30$ & 66 & 27.2 \\
\hline $31-40$ & 68 & 28 \\
\hline $41-50$ & 49 & 20.2 \\
\hline $51-60$ & 22 & 9.1 \\
\hline$>61$ & 38 & 15.6 \\
\hline \multicolumn{3}{|c|}{ Educational level } \\
\hline None & 100 & 41.2 \\
\hline Primary & 105 & 43.2 \\
\hline Junior & 23 & 9.5 \\
\hline Secondary & 14 & 5.8 \\
\hline College \& above & 1 & 0.4 \\
\hline \multicolumn{3}{|c|}{ Marital status } \\
\hline Single & 10 & 4.1 \\
\hline Married & 191 & 78.6 \\
\hline Divorced & 23 & 9.5 \\
\hline Widowed & 19 & 7.8 \\
\hline \multicolumn{3}{|l|}{ Occupation } \\
\hline Farmer & 189 & 77.8 \\
\hline Business & 42 & 17.3 \\
\hline Governmental employees & 7 & 2.9 \\
\hline non- Governmental employees & 5 & 2.1 \\
\hline \multicolumn{3}{|c|}{ Family size } \\
\hline 2 persons & 44 & 18.1 \\
\hline 3-4 person & 89 & 36.6 \\
\hline$>$ 5person & 110 & 45.3 \\
\hline \multicolumn{3}{|c|}{ Religion } \\
\hline Orthodox & 241 & 99.2 \\
\hline Muslim & 2 & 0.8 \\
\hline
\end{tabular}

\section{Knowledge of Participants' About Malaria}

All respondents knew malaria is deadly disease if left untreated. More than half $(55.6 \%)$ of the respondents have heard messages regarding malaria during the malaria season. The main sources of information about malaria were health workers/health education (49.6\%), community meeting (31.1\%), radio (16.3\%), CHA $(2.2 \%)$ and TV $(0.8 \%)$. The types of messages they heard were on usage of ITN's (47.3\%), environmental managements (49.8\%) and early treatment seeking behavior $(31.3 \%)$.

A majority (91.8\%) of the respondents knew malaria is transmitted by mosquito bite. However, other transmission routes like hunger (30.9\%) have been mentioned (Table 3). Fever was the most $(84 \%)$ recognized signs/symptoms of malaria followed by shivering/chills (60.5\%), headache and joint pain (55.6\%) and vomiting (54.3\%). Majority of the participants were aware of how to avoid malaria. The most frequently mentioned preventive methods were use of insecticide treated nets (ITN) (90.9\%) and environmental management (86.4\%) (Table 3).

Table 3: Knowledge of participants about malaria transmission, signs and symptoms and prevention.

\begin{tabular}{|c|c|c|}
\hline Variables & Frequency & Percent $(95 \% \mathrm{CI})$ \\
\hline Cause of Malaria & 261 & 111 \\
\hline Mosquito bite & 223 & $91.8(88.5-94.7)$ \\
\hline Hunger & 75 & $30.9(25.1-36.6)$ \\
\hline Eating unclean food & 19 & $7.8(4.5-11.1)$ \\
\hline Drinking dirty water & 17 & $7.0(3.7-10.3)$ \\
\hline Eating immature sugarcane & 10 & $4.1(1.6-7)$ \\
\hline Don't know the cause & 5 & $2.1(0.4-3.7)$ \\
\hline \multicolumn{3}{|l|}{ Signs and Symptoms of Malaria } \\
\hline Fever & 204 & $84(79-88.1)$ \\
\hline Shivering/chills & 147 & $60.5(54.3-66.3)$ \\
\hline Headache & 135 & $55.6(49.4-62.5)$ \\
\hline Joint pain & 135 & $55.6(49.4-62.5)$ \\
\hline Vomiting & 132 & $54.6(48.1-60.1)$ \\
\hline Loss of appetite & 73 & $30(24.3-36.2)$ \\
\hline General body weakness & 66 & $27.2(21.4-32.9)$ \\
\hline Dizziness & 60 & $24.7(19.3-30)$ \\
\hline Don't know & 2 & $0.8(0.00-2.10)$ \\
\hline \multicolumn{3}{|l|}{ Methods of Malaria Prevention } \\
\hline Using ITN's & 221 & $90.9(89.8-96.2)$ \\
\hline Environmental management & 210 & $86.4(84.7-92.8)$ \\
\hline Early treatment seeking & 67 & $27.6(22.9-34.3)$ \\
\hline \multicolumn{3}{|l|}{ Where to Seek Treatment } \\
\hline Health facility & 240 & 98.8(97.0-99.9) \\
\hline Drug vender/pharmacy & 4 & $1.6(0.40-3.70)$ \\
\hline Home remedies & 4 & $1.6(0.40-3.70)$ \\
\hline \multicolumn{3}{|l|}{ When to Seek Treatment } \\
\hline $24 \mathrm{hrs}$ & 97 & $39.9(33.7-46.50)$ \\
\hline $48 \mathrm{hrs}$ & 60 & $24.7(18.9-29.60)$ \\
\hline $72 \mathrm{hrs}$ & 39 & $16(11.50-21.00)$ \\
\hline$>72 \mathrm{hrs}$ & 47 & $19.4(14.8-25.10)$ \\
\hline
\end{tabular}

\section{Attitude of Respondents Towards Malaria}

A majority of the participants said that malaria is a public health problem in their area. All (100\%) of the respondents stated that seeking treatment as soon as the onset of signs and symptoms as well as taking a child/pregnant woman with signs and symptoms of malaria early to a health facility is important. Forty-five percent of the respondents perceived that malaria is very serious, $48.1 \%$ somewhat serious and $6.6 \%$ is not serious at all. A large number $(80.2 \%)$ of the respondents have positive attitude toward malaria 
treatment. However, $2 \%$ have mentioned that they have fear of the anti-malaria treatment consequences.

\section{Treatment Seeking Behavior}

Most of the respondents (98.8\%) sought treatment from the nearby health facility when the signs and symptoms of malaria appeared. However, only $39.9 \%$ of them sought treatment within 24 hours. Around half (47.7\%) of the study participants have experienced signs and symptoms six months prior to the study. Nine-tenth $(90.6 \%)$ of them sought treatment from health facilities, but only $22.4 \%$ reached the facilities within 24 hours.

\section{Percent Knowledge Index}

The median knowledge score of study participants was 10 . Majority (75.4\%) of the respondents had adequate knowledge on causes, signs and symptoms and prevention methods of malaria.

Table 4: Association of socio demographic variables with knowledge on malaria.

\begin{tabular}{|c|c|c|c|c|c|c|}
\hline \multicolumn{7}{|c|}{ Knowledge } \\
\hline \multirow[t]{2}{*}{ Independent } & \multicolumn{2}{|c|}{ Cause } & \multicolumn{2}{|c|}{ Signs and Symptoms } & \multicolumn{2}{|c|}{ Prevention } \\
\hline & AOR (95\%CI) & p-value & AOR $(95 \% \mathrm{CI})$ & P-value & AOR (95\%CI) & p-value \\
\hline \multicolumn{7}{|c|}{ Village } \\
\hline Emba-arba & 1 & & 1 & & 1 & \\
\hline Mai-Aynee & $2.22(2.2-18.45)$ & 0.461 & $1.30(0.28-6.13)$ & 0.737 & $0.66(0.11-4.00)$ & 0.65 \\
\hline Adi- barin & $7.75(7.45-17.90)$ & 0.072 & $2.17(0.52-9.14)$ & 0.29 & $1.61(0.27-9.60)$ & 0.604 \\
\hline Adi-hufut & $2.39(2.40-24.80)$ & 0.467 & $0.68(0.11-4.26)$ & 0.682 & $0.15(0.02-0.99) *$ & 0.048 \\
\hline Habenat & $1.98(1.98-4.98)$ & 0.66 & $0.49(0.76-3.15)$ & 0.452 & $0.06(.004-0.94)^{*}$ & 0.045 \\
\hline \multicolumn{7}{|c|}{ Sex } \\
\hline Male & 1 & & 1 & & 1 & \\
\hline Female & $1.3(0.70-15.97)$ & 0.6 & $0.65(0.23 .1 .85)$ & 0.422 & $0.43(0.09-2.10)$ & 0.298 \\
\hline \multicolumn{7}{|c|}{ Age } \\
\hline$\leq 30$ & 1 & & 1 & & 1 & \\
\hline$>30$ & $0.98(0.47-2.01)$ & 0.947 & $1.57(0.71-3.47)$ & 0.266 & $0.73(0.26-2.03)$ & 0.541 \\
\hline \multicolumn{7}{|c|}{ Marital status } \\
\hline Single & 1 & & 1 & & 1 & \\
\hline Married & $1.63(0.39-6.78)$ & 0.504 & $0.38(0.09-1.68)$ & 0.2 & $0.72(0.07-6.90)$ & 0.771 \\
\hline Divorced & $1.35(0.27-6.70)$ & 0.718 & $0.10(0.01-0.69)$ * & 0.02 & $0.66(0.06-7.70)$ & 0.744 \\
\hline Widowed & $0.69(0.13-3.62)$ & 0.663 & $0.18(0.03-1.27)$ & 0.085 & $1.60(0.12-12.6)$ & 0.721 \\
\hline \multicolumn{7}{|c|}{ Educational level } \\
\hline Literate & 1 & & 1 & & 1 & \\
\hline Illiterate & $0.29(0.18-0.63) *$ & 0.036 & $0.98(0.46-2.10)$ & 0.968 & $0.60(0.47-0.82) *$ & 0.048 \\
\hline \multicolumn{7}{|c|}{ Occupation } \\
\hline Gov't employ & 1 & & 1 & & 1 & \\
\hline Farmers & $0.95(0.85-3.21)$ & 0.491 & $2.05(0.43-9.60)$ & 0.364 & $1.02(0.1-10.3)$ & 0.984 \\
\hline Business & $0.64(1.44-2.90)$ & 0.566 & $2.91(0.60-14.1)$ & 0.184 & $1.9(0.14-24.7)$ & 0.633 \\
\hline \multicolumn{7}{|c|}{ Family Size } \\
\hline 2 persons & 1 & & 1 & & 1 & \\
\hline 3-4 persons & $0.77(0.34-1.77)$ & 0.54 & $2.03(0.73-5.61)$ & 0.174 & $2.07(0.69-6.20)$ & 0.196 \\
\hline$>5$ persons & $1.52(0.67-3.35)$ & 0.316 & $1.73(0.64-4.67)$ & 0.278 & $1.54(0.55-4.30)$ & 0.411 \\
\hline \multicolumn{7}{|c|}{ Time Needed to Reach Health Facility } \\
\hline$>30 \mathrm{~min}$ & 1 & & 1 & & 1 & \\
\hline$<30 \min$ & $1.03(0.36-2.99)$ & 0.954 & $0.7(0.212-2.24)$ & 0.536 & $0.08(0.01-0.70) *$ & 0.024 \\
\hline
\end{tabular}

Note: ${ }^{*}=\mathrm{p}<0.05$
Insert Fig 1. Here distance from the health facility was significantly associated with delay in early treatment seeking behavior ( $p$ $<0.05$ ). A multivariate logistic regression analysis showed that respondents from distant places (Adi-hufut and Habenat) had inadequate knowledge regarding the preventive methods of malaria as compared with the respondents from Emba-Arba nearer to the community hospitals $(\mathrm{p}<0.05)$. Higher educational level was significant association with knowledge of the respondents on the causes and prevention methods of malaria $(p<0.05)$. However, no association was found between educational level and knowledge on signs and symptoms of malaria ( $\mathrm{p}=0.968)$ (Table4). Illiterates were $40 \%$ less likely to know malaria prevention methods compared to literate respondents (AOR 0.60; 95\%CI: 0.47-0.82), p<0.05). A statistically significant association $(\mathrm{p}=0.024)$ was found between knowledge on prevention methods of malaria and distance from the health facility of respondents (Table 4). 
In this study respondents' occupation was significant seeking behavior of malaria was associated with higher educational association with attitude about seriousness of malaria $(p<0.001)$ (Table not shown). Farmers and businessmen were less likely to perceive the seriousness of malaria as compared with government employers (AOR=0.052; 95\%CI: 0.007-0.404), $\mathrm{p}<0.05)$ and $(\mathrm{AOR}=0.118 ; 0.017-0.815), \mathrm{p}<0.05)$ respectively. Early treatment level $(\mathrm{p}<0.05)$, distance from a health facility $(\mathrm{p}<0.05)$ and good knowledge on signs and symptoms of malaria $(\mathrm{p}=0.038)$. Those who didn't know signs and symptoms of malaria were $40 \%$ less likely than those who were aware, to seek treatment $(\mathrm{AOR}=0.6$; 95\%CI; 0.36-0.98), $\mathrm{p}<0.05$ ) (Table 5).

Table 5: Associations of socio-demographic characteristics with attitude and treatment seeking behavior of malaria.

\begin{tabular}{|c|c|c|c|c|}
\hline Independent & Attitude & $P$ value & Treatment Seeking Behavior & $P$ value \\
\hline \multicolumn{5}{|c|}{ Sex } \\
\hline Male & 1 & & 1 & \\
\hline Female & $1.92(0.20-17.98)$ & 0.569 & $1.01(0.32-3.13)$ & 0.993 \\
\hline Age & 29 & 13 & & \\
\hline$>30$ & 1 & & 1 & \\
\hline$\leq 30$ & $0.99(0.24-4.12)$ & 0.988 & $0.65(0.27-1.59)$ & 0.347 \\
\hline \multicolumn{5}{|c|}{ Educational level } \\
\hline Literate & 1 & & 1 & \\
\hline Illiterate & $0.19(0.03-1.37)$ & 0.099 & $0.65(0.51-0.26)^{*}$ & 0.006 \\
\hline \multicolumn{5}{|c|}{ Occupation } \\
\hline Govt' employ & 1 & & 1 & \\
\hline Farmers & $0.05(0.01-0.40) *$ & 0.005 & $0.99(0.23-4.32)$ & 0.991 \\
\hline Business & $0.12(0.02-0.82) *$ & 0.03 & $1.66(0.35-7.91)$ & 0.523 \\
\hline \multicolumn{5}{|c|}{$\begin{array}{ll}\text { Family Size } \\
\end{array}$} \\
\hline 2 persons & 1 & & 1 & \\
\hline 3-4 persons & $0.52(0.03-9.27)$ & 0.654 & $1.26(0.45-3.53)$ & 0.663 \\
\hline$>5$ persons & $6.03(1.30-28.2)$ & 0.23 & $1.07(0.51-2.26)$ & 0.856 \\
\hline \multicolumn{5}{|c|}{ Time Needed to Reach Health Facility } \\
\hline$>30 \mathrm{~min}$ & 1 & & 1 & \\
\hline$<30 \min$ & $5.44(0.67-4.36)$ & 0.114 & $0.34(0.14-0.83) *$ & 0.017 \\
\hline \multicolumn{5}{|c|}{ Knew Cause } \\
\hline Yes & 1 & & 1 & \\
\hline No & $1.15(0.29-4.57)$ & 0.845 & $0.90(0.44-1.87)$ & 0.784 \\
\hline \multicolumn{5}{|c|}{ Knew Signs \& Symptom } \\
\hline Yes & 1 & & 1 & \\
\hline No & $0.32(0.09-1.13)$ & 0.50 & $0.6(0.36-0.98) *$ & 0.046 \\
\hline \multicolumn{5}{|c|}{ Knew Prevention } \\
\hline Yes & 1 & & 1 & \\
\hline No & $2.17(0.35-13.40)$ & 0.406 & $2.81(.78-10.45)$ & 0.113 \\
\hline
\end{tabular}

Note: $*=p<0.05$

\section{Discussion}

A majority (91.8\%) of the respondents have mentioned that malaria is transmitted by mosquito bite, which was similar with studies from India [19], Ghana [20], and Colombia [21]. However, some of them had misconceptions like hunger, eating unclean food, drinking dirty water, and eating immature sugar cane would cause malaria. The sub-zonal branch of the ministry of health in collaboration with the national malaria control program should work to change those false believes about the causes of malaria through community health education. In this study no association between educational level of the participants and knowledge on causes and transmission of malaria. This may be due to community sensitization gaining momentum towards the sustainable development goal-3 in the community of May-Aynee administration. Similar finding was reported by a study from Ethiopia [22].

A good knowledge of respondents on the frequent signs and symptoms of malaria was reported in the present study. Fever, shivering/chills, headache, joint pain, and vomiting were stated as the cardinal signs of malaria. Fever was the predominantly (84\%) recognized symptom of malaria in this study, consistent with 
studies from India [19], Uganda [23], and Kenya [24]. This may be due to the existence of high malaria infections since long time in the area. Sensitization of the community at different occasions by health workers or CHA could also have had significant role in awareness rising of the community.

Regarding the knowledge on prevention of malaria, all study participants mentioned that malaria is preventable, similar to a study from Ghana (92.3\%) [20]. Majority (Table 3) of the study participants knew the correct practices of malaria prevention at home.Insect side treated net (ITN) was stated the most effective preventive methods of malaria, similar to other studies $[25,26]$. Advocacy on timely delivery and proper usage of ITNs together with practices on environmental management surrounding houses can serve as effective reinforcement on community's knowledge regarding malaria prevention.

Most of the respondents (97.1\%) considered malaria as a serious disease. This could be due to severity of malaria and its impact in our study area. A significant number of the participants stated that children and pregnant mothers are at higher risk of malaria that prompt treatment is crucial for their survival. However, studies in Colombia and Uganda reported that only a small proportion felt malaria as a serious and life-threatening condition, with $45.8 \%$ of Colombians and $44.6 \%$ of Ugandans considering it as a normal disease [21,23].In this study, a significant association was found between perceptions of the study subjects on seriousness of malaria with occupation $(p<0.05)$ (Table 5). Farmers and businessmen thought that malaria was not serious. This may be due to lack of knowledge attributed to limited access to information as compared with government employees.

Ninety percent of the present study participants, who had experienced signs and symptoms of malaria six months prior the study, have visited health facility for consultation. This is much higher compared to other studies, only $38.5 \%$ in Nigerians [27] and $54.2 \%$ in Ghanaians [20] have sought treatment from a health facility. Timing of treatment seeking behavior $(<24 \mathrm{hrs})$, among subject experienced signs/symptoms of malaria was very low $(22.4 \%)$. One of the main challenges in seeking treatment on time was distance to reach the health facilities. People had to travel long distances to get treatment, because there were only few number of government health facilities. Distance from health facility $(\mathrm{P}<0.05)$, educational level and knowledge on sings and symptoms of malaria $(\mathrm{P}<0.05)$ were found having significant association with early treatment seeking behavior. Although the knowledge and attitude of the residents in May-Aynee administration was adequate, practices of early treatment seeking behavior of malaria was low. This also could be due to community's inability to distinguish malaria's symptoms with other similar diseases such as dengue fever and other febrile illness in the first two days of onset of the illness. Similar findings were reported by studies from rural Ethiopia [22] and Myanmar [28].
Needless to mention, a small proportion (5.1\%) of the respondents used traditional remedies like Aloe Vera, Teketater, eating bitter food and others to treat malaria. This is similar to a study from Myanmar [28], where 7.3\% sought treatment from traditional healer as well as a friend or relative. Another study from Ghana [20] revealed that some of the respondents used Neem or Pawpaw, bark of Mahogany trees to treat malaria at their home. However, in Nigeria, a large proportion (61.5\%) of study participants in preferred to seek traditional healers for being not expensive [27]. Therefore, an understanding of community's knowledge and practice regarding malaria prevention and treatment are important in assessing the situation before designing intervention projects.

\section{Limitation}

For the reason of limited budget, we did not conduct large household sample size besides of the distance from the workplace of the researchers.

\section{Conclusion}

It is evident that communities' knowledge, attitudes and practices about malaria often remains unobserved during malaria control efforts. Knowledge on causes, signs and symptoms and prevention aspects of malaria was found to be high, but early treatment seeking behavior within the recommended time was low. Some misconceptions were also prevalent among the residents of May-Aynee administration. Further, the distance to reach health facilities was an impediment to seeking treatment promptly. Thus, effective health promotion and education activities should be implemented to increase the likelihood of timely treatment of malaria. Simultaneously, efforts should be made to reduce the distance between home and health care facilities. This can also be done by increasing the number of health facilities.

\section{Ethical Consideration}

Ethical approval was obtained from the ethical committee of the Asmara College of Health Sciences. A letter of consent was written to the local administrators. Before the interview, a verbal consent was obtained from participants, and were assured on confidentiality of the information.

\section{Conflict of Interest}

The authors declare that they have no conflict of interest

\section{Authors' contributions}

AKA and EAK designed the research, AKA and MWW analyzed the data, BEW, MWW, NYT and LFS wrote the first draft of the paper; AKA and EAK edited the paper; AKA was the principal investigator. All authors contributed to the interpretation of results and approved the final manuscript.

\section{Acknowledgement}

The authors acknowledge the constant and continuous support received from the Asmara College of Health Sciences and School of 
Public Health. We are grateful to the local administration of MayAynee and the study subjects for their collaboration and voluntary participation in the study.

\section{References}

1. Simon I Hay, Carlos A Guerra, Andrew J Tatem, Abdisalan M Noor, Robert W Snow (2004) The global distribution and population at risk of malaria: past, present, and future. Lancet Infect Dis 4(6): 327-336.

2. (2016) World Health Organization: World Malaria Report, Geneva, Switzerland.

3. (2017) World Health Organization: World Malaria Report, WHO 2017, Geneva, Switzerland, pp. 196.

4. (2015) World Health Organization; World Malaria Report, Geneva, Switzerland.

5. (2000) World Health Organization: WHO expert committee on malaria: twentieth report. Technical Report Series No. 892. Geneva, Switzerland.

6. (2010) World Health Organization: World Malaria Report, Geneva, Switzerland.

7. (2010) World Health Organization. Guidelines for the Treatment of Malaria ( $\left.2^{\text {nd }} E d n.\right) .2010$ Geneva, Switzerland.

8. (2013) World Health Organization. World Malaria Report, Geneva, Switzerland.

9. (2012) World Health Organization: World Malaria Report, Geneva, Switzerland.

10. Malaria \& Sustainable Development Goals.

11. (2008) Ministry of health, National Malaria Control Program, Eritrea Malaria indicator survey 2008.

12. (2011) World Health Organization: World Malaria Report, 2011 Geneva: Switzerland.

13. https:// Eritrea-working-towards-total-malaria-eradication

14. https://www. eritrea-made-breakthrough-in-preventing-malariaprevalence-in-history

15. Tynan A, Atkinson JA, Toaliu H, Taleo G, Fitzgerald L, et al. (2011) Community participation for malaria elimination in Tafea province, Vanuatu: Part ii. Social and cultural aspects of treatment seeking behavior. Malar J 10: 204.

16. Mohan V, Shanthirani CS, Deepa M, Datta M, Williams OD, et al. (2006) Community Empowerment-A Successful Model for Prevention of Noncommunicable Diseases in India-the Chennai Urban Population Study (CUPS-17). Journal of Association Physician of India 54: 858-862.

ISSN: 2574-1241

DOI: 10.26717/BJSTR.2019.22.003700

Amanuel Kidane Andegiorgish. Biomed J Sci \& Tech Res

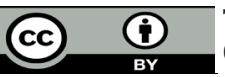

This work is licensed under Creative

Commons Attribution 4.0 License

Submission Link: https://biomedres.us/submit-manuscript.php
17. Motohashi Y, Kaneko Y, Sasaki H, Yamaji M (2007) A decrease in suicide rates in Japanese rural towns after community-based intervention by the health promotion approach. Suicide Life Threat. Behav 37(5): 593599.

18. Geounuppakul M, Butraporn P, Kunstadter P, Leemingsawat S, Pacheun O (2007) An empowerment program to enhance women's ability to prevent and control malaria in the community, Chiang Mai Province, Thailand. SouthEast Asian J Trop Med Public health 38(3): 546-559.

19. Yadav SP, Yadav S, Kuma P, Yadav S (2013) Knowledge, treatmentseeking behaviour and socio-economic impact of malaria in the desert ofRajasthan India. South Afr J Epidemiology Infect 28(1): 41-47.

20. Laar A S, Laar AK, Dalinjong PA (2013) Community perception of malaria and its influence on health-seeking behavior in rural Ghana: a descriptive study. MWJ 4: 1 .

21. Forero D, Chaparro P, Vallejo A, Benavides Y, Gutiérrez J, et al. (2014) Knowledge, attitudes and practices of malaria in Colombia. Malaria Journal 13: 165

22. Nagasa Dida, Birhanu Darega, Amene Abebe (2015) Treatment seeking behavior and associated factors among malaria suspected patients in Bale Zone, Southeast Ethiopia:Institution-based cross-sectional study. J Fam 2(1): 5

23. Luyiga Faridah Mwanje (MAKSPH-CDC Fellow) (2013) Knowledge, attitudes and practices on malaria prevention and control in uganda. A case study of nsaabwa village, mukono district. Uganda.

24. Mutua EN, Bukachi SA, Bett BK, Estambale BA, Nyamongo IK (2016) Lay knowledge and management of malaria in Baringo country Kenya. Malar J 15(1): 486.

25. EAtieli HE, Zhou G, Afrane Y, Lee MC, Mwanzo I, et al. (2011) Insecticide treated net (ITN)ownership, usage,and malaria transmission in the highlands of western Kenya. Parasite Vectors 18: 113.

26. Hawley WA, Ter Kuile FO, Steketee RS, Nahlen BL, Terlouw DJ, et al. (2003) Implications of the western Kenya permethrin-treated bed netstudy for policy,program implementation, and future research. Am J Trop Med Hyg 68(4): 168-173.

27. AP Agu, JO Nwojiji (2005) Childhood malaria mothers' perception and treatment seeking behaviour in a community in Ebonyi State, South East Nigeria. Journal of Community Medicine and Primary Health Care 17(1): 45-50.

28. Xu JW, Xu QZ, Liu H, Zeng YR (2012) Malaria treatment-seeking behaviour and related factors of Wa ethnic minority in Myanmar: a cross-sectional study. Malar J 11: 47.

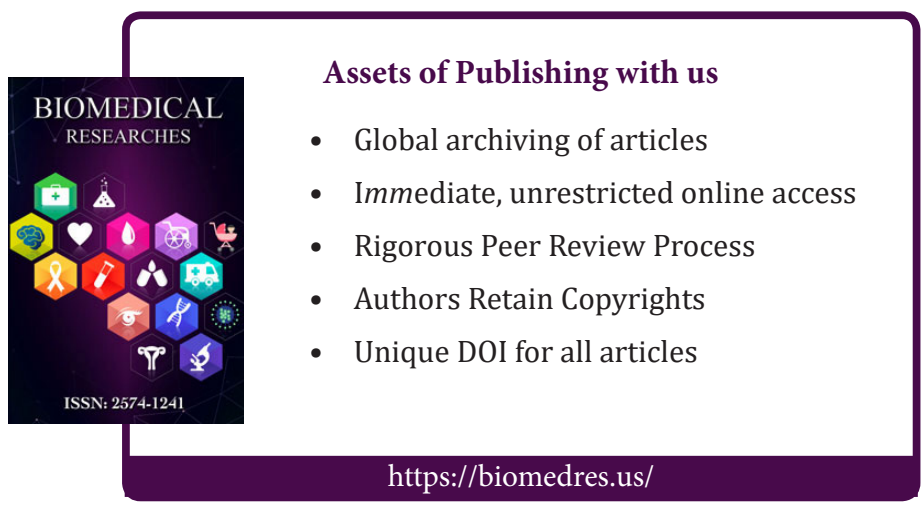

